This is an Accepted Manuscript of an article published by Taylor \& Francis in Journal of Gerontological Social Work on 2021-06-01, available online:

https://doi.org/10.1080/01634372.2021.1933293. Access to this work was provided by the University of Maryland, Baltimore County (UMBC) ScholarWorks@UMBC digital repository on the Maryland Shared Open Access (MD-SOAR) platform.

Please provide feedback

Please support the ScholarWorks@UMBC repository by emailing scholarworks-group@umbc.edu and telling us what having access to this work means to you and why it's important to you. Thank you. 


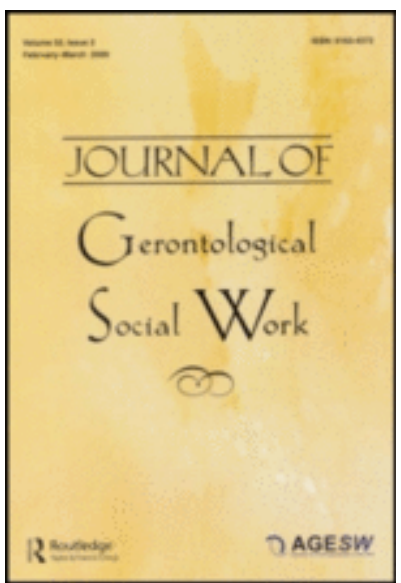

\section{Structural Characteristics of Nursing Homes and Social Service Directors that Influence Their Engagement in Disaster Preparedness Processes}

\begin{tabular}{|c|l|}
\hline Journal: & Journal of Gerontological Social Work \\
\hline Manuscript ID & WGER-2020-1694.R4 \\
\hline Meywords: & $\begin{array}{l}\text { Health care workforce, Long-term care, Natural and human-made } \\
\text { disasters, Skilled nursing homes, institutional care }\end{array}$ \\
\hline Abstract: & $\begin{array}{l}\text { Nursing home residents are an at-risk population during disaster } \\
\text { situations, and nursing homes face unique challenges in managing } \\
\text { disasters. Nursing home social service departments can support their } \\
\text { nursing homes in meeting the needs of residents during disasters, yet } \\
\text { there is little research exploring their involvement. To address this gap, } \\
\text { we use secondary data from the 2019 National Nursing Home Social } \\
\text { Service Directors' study to explore social service directors' and their } \\
\text { departments' involvement in disaster preparedness and response, and } \\
\text { personal- and nursing home-level characteristics that predict } \\
\text { involvement. Results show that nursing home social service directors and } \\
\text { their staffs are predominantly involved; 61.9\% (n= 562) of respondents } \\
\text { stated always participating, and an additional 20.3\% (n=184) usually } \\
\text { participating in disaster planning. The age of the director significantly } \\
\text { predicted involvement, with older directors being most likely to always } \\
\text { be involved. Further research is needed to understand why some nursing } \\
\text { homes involve their social service directors in disaster planning and } \\
\text { others do not, what roles those directors play, and to identify strategies } \\
\text { to increase involvement within this role. }\end{array}$ \\
\hline
\end{tabular}

\section{SCHOLARONE" Manuscripts}




\section{Address correspondence to:}

Nancy Kusmaul, University of Maryland Baltimore County, 1000 Hilltop Circle, Sherman Hall

322, Baltimore, MD 21250, nkusmaul@umbc.edu

Funding for data collection was provided by the RRF Foundation for Aging, in a grant to Mercedes Bern-Klug, University of Iowa. 


\begin{abstract}
Nursing home residents are an at-risk population during disaster situations, and nursing homes face unique challenges in managing disasters. Nursing home social service departments can support their nursing homes in meeting the needs of residents during disasters, yet there is little research exploring their involvement. To address this gap, we use secondary data from the 2019 National Nursing Home Social Service Directors' study to explore social service directors' and their departments' involvement in disaster preparedness and response, and personal- and nursing home-level characteristics that predict involvement. Results show that nursing home social service directors and their staffs are predominantly involved; $61.9 \%(n=562)$ of respondents stated always participating, and an additional 20.3\% $(\mathrm{n}=184)$ usually participating in disaster planning. The age of the director significantly predicted involvement, with older directors being most likely to always be involved. Further research is needed to understand why some nursing homes involve their social service directors in disaster planning and others do not, what roles those directors play, and to identify strategies to increase involvement within this role.
\end{abstract}


Compared to older adults in the community, nursing home residents are at greater risk for adverse outcomes during disasters, in part due to older age and having more chronic conditions (Dosa et al., 2012). Nursing home residents often have functional limitations in activities of daily living (ADLs) and instrumental activities of daily living (IADLs), physical disabilities, and/or cognitive impairments that impact their ability to evacuate safely during disasters (Aldrich \& Benson, 2008; Holup et al., 2017; Lu et al., 2020).

Nursing home social service departments "provide medically-related social services to attain or maintain the highest practicable physical, mental and psychosocial well-being of each resident" (Behavioral Health Services, 2016, para a). They also comprise essential parts of the interdisciplinary teams. Each nursing home approaches disaster preparedness differently, from what disciplines comprise the team to the role each plays in planning, practice/drills, and response (Office of Inspector General, 2012a). The Centers for Medicare and Medicaid Services (CMS) provides guidance in the form of a checklist (81 F.R. 68692, 2016), which lays out what contingencies should be addressed in a nursing home's emergency plan but does not include which disciplines within the nursing home should be involved. Social services should be an important part of the plan, as the checklist calls for "Training ... to address psychological and emotional aspects on caregivers, families, residents, and the community at large" (Office of Inspector General, 2012b, p.33). Other key elements of the regulation are procedures to assess for relevant hazards and developing interventions for each hazard; plans for communication with families, residents, transportation and other vendors; and instructions for policies and procedures to address the same.

Nursing homes face all types of hazards in disasters. While the CMS checklist does not designate which disciplines should be involved in disaster preparedness, the skills that bachelor's 
and master's prepared social workers bring to the long-term care environment, such as broker, advocate, manager, educator, facilitator, and organizer (e.g., Hepworth et al., 2013) could be particularly useful in helping nursing homes prepare for disasters. Nursing home social service directors, who may or may not be social workers, must understand micro, mezzo, and macro issues, be aware of person-in-environment, and have crisis management skills, all of which are essential components of social work education (Council on Social Work Education, 2015). Nursing homes with more qualified social service employees receive fewer psychosocial deficiencies on state inspection surveys (Simons, 2006).

Federal regulations require nursing homes with at least 120 beds that accept Medicare or Medicaid funds to have at least one full-time social worker, yet the definition of social worker includes people who are not educated or credentialed in social work. The regulatory definition of a social worker includes those with bachelor's degrees in gerontology, sociology, special education, rehabilitation counseling, and psychology (Administration, 2019). The National Association of Social Workers (NASW) recommends, at minimum, a nursing home social worker have a degree in social work (Bailey et al. 2003). We will discuss further in the literature review what makes social workers well suited to help in these activities.

Natural disasters are commonly defined by nursing home staff and researchers as events like hurricanes, tornadoes, and snowstorms, with the potential to physically damage buildings, disrupt the supply chain, and strand staff at work or away from the nursing home for extended periods of time (Goldman \& Galea, 2014). This article uses data from the National Nursing Home Social Services Directors' (NNHSSD) study, a nationally representative survey designed to characterize the nation's social services workforce, to describe the personal-level and nursing home-level structures that influence how often nursing home social service directors and their 
staffs are involved in the process of nursing home disaster preparedness. We also discuss the importance of including nursing home social service directors and workers in disaster preparedness and response and the strengths social workers can bring to these roles.

\section{Literature Review}

\section{Nursing Homes and Disaster Preparedness and Response}

With the exception of hospitals, nursing homes provide the highest level of care for older adults of any other setting. The frailty of this population decreases their ability to withstand negative situations that may occur before, during, and after disasters, such as gaps in care from personnel shortages, extreme changes in temperature, loss of necessary medical equipment due to power outages or floods, and sudden and unpredictable changes in setting or location, which can exacerbate confusion, agitation, and behavioral concerns (Brown et al., 2007; Fernandez et al., 2002).

The unique vulnerabilities of nursing home residents to disasters were highlighted during Hurricane Katrina in 2005, when approximately 139 nursing home residents died during and after the hurricane (Hyer et al., 2007). Subsequent studies exploring the morbidity and mortality impacts of being exposed to hurricanes indicate that the hurricane had long-term effects on nursing home residents (Dosa et al., 2010). Hurricane Katrina and its' ill effects revealed significant gaps in nursing homes' policies and planning and preparedness processes. A report issued by the Office of Inspector General (OIG) (2006) indicated a breakdown had occurred in the planning process across all the Gulf States (Alabama, Florida, Louisiana, Mississippi, and Texas) that experienced a major hurricane in 2004 or 2005 (Ivan, Katrina, Rita, and Wilma). Factors contributing to breakdowns in preparedness and response included nursing homes not having adequate plans, administrators failing to follow through with planned processes, or plans 
not being sufficient to meet emerging needs during disasters. Nursing home administrators also reported that their exclusion from local, state, and federal planning efforts resulted in a lack of resources and supports during the disaster and that plans for older adults were inconsistent across the care continuum (Ladika et al., 2008).

\section{The Potential Merits of Social Work in Disaster Planning and Response}

Although social workers have often responded to disasters and traumas (Hamler et al., 2020; Kusmaul et al., 2018; Naturale, 2007; Scoville, 1942), there is a dearth of research specifically examining the role of social work in disaster response in nursing homes. Much of the existing literature discusses events that occurred over a decade ago, such as Hurricanes Katrina, Rita, and Gustav, or is conceptual (Beltran et al., 2020). These studies describe social work's role as supporting the emotional well-being of residents, and also that of overwhelmed, tired, and distressed direct care staff to ensure the team can function effectively under duress (Laditka et al. 2008). Social workers engage in disaster management activities throughout all stages of the disaster. For example, they provide individualized support to residents experiencing psychological distress from seeing news coverage about the impending events, restore communication with families (e.g., after evacuating to another location), and facilitate the processing of shared trauma (Claver et al., 2013; Laditka et al., 2008). As part of the interdisciplinary team, social workers are often the profession tasked with ensuring residents' emotional well-being. Nursing home administrators identify social work as the profession most likely to engage in resilience-building interventions such as psychological first aid training to support nursing home residents during disasters (Brown et al., 2010).

Other critical roles of nursing home social service workers are facilitating discussions about goals of care, resolving family conflicts, and documenting advance care planning wishes 
(Bomba et al., 2011). Ensuring resident goals are documented and up to date is crucial during disasters, as decisions may need to be made urgently or while communication with decisionmakers is disrupted. Social workers collaborate with other members of the interdisciplinary team and outside agencies (e.g., hospice agencies), to plan for continuity of supports during disasters. Following a disaster, social workers support residents who have experienced a change in condition and their families; this may involve additional discussions around goals, and coordination of end-of-life care (Frahm et al., 2012).

\section{Theoretical Framework}

Donabedian's structure, process, and outcome model (Donabedian, 1988) for evaluating the quality of care is used as a framework to organize this exploratory study. Donabedian proposed that favorable client outcomes, or good quality care, results from effective processes, which are shaped by structural factors. Structures of healthcare include provider and organizational-level characteristics such as capacity (i.e., bed size, staffing); processes include how and what services are delivered; and outcomes are care quality and patient physical and psychosocial well-being. As described in the literature review, previous studies have highlighted the poor quality of disaster response in nursing homes, which is the Donabedian outcome of focus in our research. In this exploratory study, we focus on the role of facility-level and social service director-level characteristics (structure) on involvement in disaster preparedness (process).

Despite the potential for nursing home social service directors to engage in disaster preparedness and response, their level of involvement in this work within nursing homes has not been clearly described (Beltran et al., 2020). There are even fewer studies that speak directly to nursing home social service directors' and staffs' involvement in disaster preparedness. The 
current study helps to bridge this gap, by exploring nursing home social service directors' involvement in the process of disaster planning and response and the structural factors associated with that involvement.

\section{Methods}

\section{Data Source}

We used a subset of the NNHSSD study to describe whether nursing home social service workers help their nursing homes prepare for disasters and the personal-level and nursing homelevel characteristics that influence that involvement. The NNHSSD study provides nationally representative data from nursing home social service directors to characterize the nation's nursing home social services workforce, describe their workload, and determine their training needs and preferences (Bern-Klug et al., 2021). The total survey had 185 items.

Of the 3,067 nursing home social service directors contacted by the NNHSSD study, 924 completed the study survey, for a response rate of $30 \%$. The distribution of responses in the overall sample is reported in (Bern-Klug et al., 2021). Importantly, the nursing home characteristics of the respondents were representative of nursing homes nationally across multiple factors including the type of nursing home, ownership, bed size, chain status, and quality rating (Bern-Klug et al., 2021).

\section{Variables}

\section{Outcome Variables}

The primary outcomes we used are based on two items. The first item asked social service directors the extent to which social services staff "participate in disaster response planning and drills." Possible responses were "always", "usually", "sometimes", and "never". In our analysis, we combined sometimes and never due to the size of the samples, $12(n=109)$ and 
six $(n=56)$ percent, respectively, much smaller than the usually and always groups. The second item asked social service directors how much preparation time they would need in order to provide one-on-one training to a social services colleague to "explain the social services' role in disaster planning and during a disaster." Response options were "could do without preparation", "2 hours prep time", "10 hours prep time", or "could not do." This variable, particularly the "could not do" response, served as a proxy for whether or not they needed training themselves.

\section{Predictor Variables}

Predictor variables were selected to allow us to explore structural factors that might influence whether or not social service directors were involved in the disaster preparedness planning process. Due to the exploratory nature of this work, variables included were selected based on previous literature indicating their influence on nursing home processes and outcomes (e.g., Castle \& Ferguson, 2010; Schnelle et al., 2004). We grouped the structural variables into individual-level factors and nursing home-level factors. Individual-level factors were education level, years of experience, whether the person had a social work degree and license or not, gender, race, and age. Demographic characteristics allow us to describe the sample. Other individual characteristics were based on the literature and NASW recommendations describing desired structural qualifications of social service staffing. To reduce respondent burden, nursing home-level factors were obtained from public access files on the CMS website. Nursing homelevel variables were bed size, staffing ratio, ownership, location, and rural/urban designation. These structural variables have been shown in previous research to impact outcomes for nursing home residents (Shippee et al., 2015).

Individual Variables. The NNHSSD study collected information on social service directors and their staffs, as reported by the directors. We used information only about the 
directors themselves. Individual-level variables were kept as the NNHSSD study coded them.

Education level was coded into three categories: less than a four-year degree, Bachelor's degree, and Master's degree. Years of experience was coded into three categories: 0-3 years, 4-9 years, and 10 or more years. Social work degree and license were coded as to whether the respondent had both a social work degree and a social work license (yes or no). Gender was coded as male and female. Race was coded into two categories: White and non-White, given the high percentage of White respondents $(88.0 \%)$ in this sample. Age was collected as categorical, into ages 18-34, 35-54, and 55 and older.

Bed Size. Bed size refers to the number of Medicare and/or Medicaid certified beds. The NNHSSD study collapsed this into a categorical variable of $0-60,61-120$, and $120+$. These cut points reflect two structural factors. The average size of a nursing home in the United States is 106 beds; only one state has an average of fewer than 60 beds (Kaiser Family Foundation, 2019). Therefore, the $0-60$ bed category was created to capture staffing differences that may occur in smaller homes. The cut point at 120 was due to the regulations that require a "full-time qualified social worker" in nursing homes with more than 120 beds (Administration, 2019).

Staffing Ratio. We calculated staffing ratio by dividing number of full-time equivalent social service staff by number of residents in the nursing home and then multiplying by 100 .

Ownership. The CMS website lists 13 categories of tax status. For the NNHSSD study, these were collapsed into "for-profit", "not-for-profit", and "government."

Location. Researchers from the NNHSSD study obtained state level data on each nursing home and included it in the data set. Since this study looked at disaster preparedness, we collapsed the states into categories described as "Northeast Coastal" (mid-Atlantic and north), "South Coastal" (Gulf coast and southeastern U.S.), "West Coastal" (states that border on the 
Pacific Ocean), and "non-coastal" (all other states that do not border an ocean). We based these categories on the different types of potential disasters each was most likely to face, which we hypothesized would lead to differences in preparedness. We later re-categorized these into a new variable to examine differences in "Wildfire" versus "non-Wildfire" regions. The Wildfire category included Oregon, Washington, California, and Colorado, and non-Wildfire included the remaining states.

Rural/Urban. The NHHSSD study used county-level data to assign one of nine RuralUrban continuum codes (RUCC) as designated by the USDA to each participating nursing home. For our analysis, the nine RUCC categories were collapsed into a dichotomous variable of "metro" and "non-metro," with metro as the reference category.

\section{Statistical Analyses}

We first ran Chi-square analyses to test the association between categorical predictors and both outcome variables. We intended to run hierarchical logistic regression models for both outcome variables. However, the bivariate analysis showed no statistically significant results for the question on how much preparation time Social Service Directors would need in order to provide one-on-one training to a social services colleague to "explain the social services' role in disaster planning and during a disaster", so we only ran a hierarchical logistic regression model for the "participate in disaster response planning and drills" question. The first step of the model included individual variables, and the second step added nursing home structural variables. We then ran an additional unanticipated regression model where we replaced the location variable of Coastal/non-Coastal with Wildfire/non-Wildfire. We conducted all analyses in IBM SPSS Version 26.

\section{Results}




\section{Descriptive Statistics}

A full description of the sample can be found in Bern-Klug et al.(2021). Broadly, the sample demographics are similar to national trends in nursing home social work: mostly female $(93.1 \%, n=523)$ and White $(87.3 \%, n=495)$. Slightly less than half were between the ages of 35 $54(45.9 \%, n=258)$, one quarter were $18-34,(24.9 \%, n=140)$, and the remainder were over the age of $55(29.2 \%, n=164)$. The majority of the sample was college educated: $47.8 \%(n=267)$ reported a bachelor's degree as their highest level of education and 34.8\% $(n=194)$ reported a master's degree. Just over half had a degree in social work either at the BSW or MSW level $(55.6 \%, n=310)$, but only a third had both a social work degree and a social work license $(34.2 \%$, $\mathrm{n}=191$ ), reflecting the lack of social work requirements for social service directors in nursing homes.

\section{Social Service Involvement in Disaster Planning and Drills}

Responses to the question, the extent to which social services staff "participate in disaster response planning and drills," indicated that the vast majority of social services departments participate in disaster training: $61.9 \%(n=562)$ of respondents reported the department always participates, $20.3 \%(n=184)$ usually, and $17.8 \%(n=162)$ sometimes or never participated. In fact, only six percent reported that the social services department never participated in disaster response planning and drills.

\section{Directors' Ability to Explain Social Services' Role in Disaster Planning and During a}

\section{Disaster}

The question about how much preparation time a social service director would need to explain the social services' role in disaster planning and during a disaster served as a proxy for whether the social service directors felt competent in their knowledge of disaster preparedness 
and response. Most directors felt fairly competent: $38.6 \%(\mathrm{n}=357)$ could explain the social services role with no preparation, $47 \%(n=434)$ needed less than two hours to prepare. The remaining $11 \%$ either needed 10 or more hours to prepare $(7 \%, \mathrm{n}=65)$ or felt that they could not do at all $(4 \%, \mathrm{n}=37)$. We conducted bivariate analysis to determine whether structure or process variables influenced the social service director's preparedness. A lack of significant responses led us to conclude that they did not.

\section{Chi-Square Models}

\section{Individual-Level Structures}

Chi square tests were used for categorical predictors. Age of the social services director was a statistically significant predictor of always being involved in disaster planning and drills $X^{2}(4, N=908)=20.557, p<.001$, with the oldest nursing home social service directors most likely to be always involved. See table 1 for the results of the other individual-level predictors, none of which showed evidence of statistical differences by group. [Insert table 1 about here]

\section{Nursing Home Structures}

Among the nursing home level predictors, size of the nursing home predicted social services involvement in disaster planning and drills $X^{2}(4, N=908)=9.812, p=.04$ with social service workers in large size nursing homes (more than 120 beds) more likely to endorse that they were only never or sometimes involved.

\section{Regression Model}

Table 2 presents results from the hierarchical logistic regression model used to determine the likelihood that social workers were always involved in nursing home disaster preparedness and response, with individual-level and nursing home-level characteristics added at each step of the model. In step one, the individual-level characteristics were statistically significant, $X^{2}(9)=$ 
$27.740, \mathrm{p}=.002$. The model explained $4.0 \%$ (Nagelkerke $R 2$ ) of the variance between being always involved (vs all other responses) in disaster preparedness and response and correctly classified $61.0 \%$ of cases. Age of the social service director was a statistically significant predictor of involvement in disaster preparedness and response. Compared to those age 55 and older, social service directors ages $18-34(\mathrm{OR}=.46,95 \% \mathrm{CI}[.29, .71], p<.001)$ and ages $35-54$ $(\mathrm{OR}=.51,95 \% \mathrm{CI}[.36, .73], p<.001)$ were less likely to be involved in disaster preparedness and response. The addition of the nursing home level characteristics in the second step was not statistically significant. Step two added only $1.1 \%$ of additional explanation of the variance (Nagelkerke $R 2$ ). No single nursing home characteristic was statistically significant in explaining variance. The unanticipated regression model with Coastal/non-Coastal replaced by Wildfire/non-Wildfire revealed no additional statistically significant findings. [Insert table 2 about here]

\section{Discussion}

Our findings reveal that most nursing home social services departments (61.9\%) are always involved in disaster planning and another 20.3 percent usually are-accounting for social services departments involvement in $80 \%$ of all U.S. Medicare and/or Medicaid certified nursing homes' disaster planning. Federal guidelines require nursing homes to train all of their staff every year on emergency and disaster plans (81 F.R. 68692, 2016), thus while not confirmed from this survey, it is likely the social services department is working with other departments in disaster planning. Interdisciplinary disaster planning would likely yield the best results for residents, because every department is impacted by a disaster, and all staff are needed for a comprehensive, multidimensional response. Interdisciplinary interventions in nursing homes have been shown to improve resident outcomes in other areas (Nazir et al., 2013). Strengthening 
federal guidelines for social service staffing and for interdisciplinary team participation in disaster planning is one structural change that might influence this process for nursing homes.

There are a number of limitations that should be considered when interpreting the findings of this study. First, methodologically, this data was collected using a self-report survey and reflects the perceptions of the social service directors who responded. Further, the outcome measure was double-barreled and may have inaccurately measured their participation. Future research should break out survey items. For example, "participate in disaster response planning" and "drills" could be listed as separate items to more accurately determine the nursing home social service departments' involvement in disaster planning. We also found that older social service directors were more likely to participate but we do not know their exact ages due to how the age was collected. We also do not know if age correlates to greater experience. Our only statistically significant result, age, was collected as a categorical variable. However, despite these limitations, this exploratory study of secondary data provides valuable insight into the involvement of social service directors and their staff in disaster preparedness of nursing homes.

Our statistical model was not successful in identifying structural predictors of social services departments' participation in disaster planning and drills. Indeed, neither characteristics of the social services director (other than the age of the director), nor the structural characteristics of the nursing home helped to explain the variation in social services department participation in disaster planning and drills. Our findings indicate that older nursing home social service directors were more likely to report their department was involved in disaster planning as compared with their younger counterparts. There is some research that found that social workers who remain in the profession are older (Wermeling, 2013) and that social workers who remain in the profession turnover frequently (Chiller \& Crisp, 2012). Neither of these studies looked at nursing home 
social service directors. This would be interesting to explore further, to understand whether older social service directors have more experience, and as discovering the reasons might help nursing home administrators engage younger nursing home social service directors in disaster planning and drills. Understanding barriers to engagement among younger nursing home social service directors may also reveal training opportunities.

The data used in this study was collected pre-COVID. The COVID-19 global pandemic has been a completely different kind of disaster to which nursing homes have had to respond. During COVID-19 the roles of nursing home social service directors and their staffs have been similar to previous natural disasters such as facilitating communication between residents and their families and providing emotional support to both parties. In addition, the COVID-19 global pandemic has been prolonged, has left residents and staff particularly vulnerable to physical harm due to limited access to personal protective equipment (PPE), and has created additional psychosocial needs related to social isolation and separation from family members (e.g., Kusmaul et al., 2020). Since experts say that global pandemics may become more common in the future (David \& LeDevedec, 2019), disaster preparedness and response must incorporate the lessons learned from COVID-19, including the essential role of social service departments in disasters.

\section{Implications for Social Work in Long Term Care}

The most concerning part of our finding was that five percent of nursing home social service directors were never involved in disaster planning and drills and $12 \%$ were only sometimes involved. While these nursing homes are likely still engaged in disaster planning, the social service directors were absent from these activities. Due to all of the reasons discussed about how nursing home social service directors can contribute to a nursing home's disaster 
planning, this finding suggests that the absence of social workers from this process could be shaping the quality of the outcomes. While this study did not allow us to explore this possibility, this is a structural factor that is worth exploring in future research.

Previous studies on disaster preparedness in nursing homes have found that lack of personal knowledge about disasters and limited nursing home financial resources were cited as two of the most common barriers to preparedness and planning (Dosa et al., 2003). Social workers often feel unprepared to respond in the immediate aftermath of a disaster since few social workers are trained to act in a community-wide disaster (Newhill \& Sites, 2000). While many social workers are not specifically trained in disaster preparedness, it is essential that social work education prepare all new social work professionals to be competent and ready to assist older adults during a disaster. This is particularly prevalent as so many social work roles intersect with older adults in disaster preparedness, response, and recovery.

The COVID-19 global pandemic and resultant impacts on nursing homes have shown us that social service workers are an important part of a nursing home's disaster response. COVID19 has isolated residents from family members, and many residents have gotten sick and died. Social workers have been responsible for supporting isolated residents and concerned family members often with few resources because leadership and other disciplines have little understanding of what they do (Kusmaul et al., 2020; Miller et al., 2021). Moving forward, it will be important to understand the training and support needs of nursing home social workers, to ensure that they can fulfill their duty of supporting residents' well-being, resident rights, and dignity during disasters.

Additional research is needed on social workers in long-term care settings. Further research is necessary to explain why some nursing homes include their social services 
departments in disaster training and others do not. It is also important to document whether nursing homes that consistently include social services in disaster planning processes experience better disaster-related outcomes for residents. Future studies should investigate the role that nursing home social services staff members play in disaster planning and during a disaster. 


\section{References}

Administration, 42 C.F.R. $§ 483.70$ (2019). https://www.ecfr.gov/cgi-bin/textidx?SID=d224cefa 707cdfdeac2aa290bd4472d3\&mc=true\&node $=$ sp42.5.483.b\&rgn $=$ div 6\#se42.5.483_140

Aldrich, N., \& Benson, W. F. (2008). Disaster preparedness and the chronic disease needs of vulnerable older adults. Preventing Chronic Disease, 5(1). https://www.cdc.gov/pcd/issues/2008/jan/pdf/07 0135.pdf

Bailey, G., Clark, E., Kaye, L., Torres, J. Nagle, P., Avery-Edwards, M., Frank, L., Hall, A. P., Kleinman, A., Miller, W., Morano, C., Dishler Shubin, S., Hines Smith, S., Whitaker, T., \& Yagoda, L. (2003). National Association of Social Workers Long-Term Care Facilities Standards Task Force. National Association of Social Workers.

Behavioral Health Services, 42 C.F.R. $§ 483.40$ (2016). https://www.ecfr.gov/cgi-bin/text$\mathrm{idx} ? \mathrm{SID}=\mathrm{d} 224 \mathrm{cefa} 707 \mathrm{cdfdeac} 2 \mathrm{aa} 290 \mathrm{bd} 4472 \mathrm{~d} 3 \& \mathrm{mc}=$ true $\&$ node $=\mathrm{sp} 42.5 .483 . \mathrm{b} \& \mathrm{rgn}=\mathrm{div}$ 6\#se42.5.483_140

Beltran, S., Luigi, P., \& Kusmaul, N. (2020). Rising above the flood: Emergency management and gerontological social work. Innovation in Aging, 4(1), 65-66. https://doi.org/10.1093/geroni/igaa057.214

Bern-Klug, M., Smith, K., Roberts A.R., Kusmaul, N., Gammonley, D., Simons, K., Galambos, C., Hector, P., Bonifas, R., Herman, C., Downes, D., Munn, J., Rudderham, G., Cordes, E., \& Connolly, R. (2021). About One-Third of Nursing Home Social Services Directors have Earned a Social Work Degree and License. Journal of Gerontological Social Work. Advance Online Publication. https://doi.org/10.1080/01634372.2021.1891594 
Blanchard, G., \& Dosa, D. (2009). A comparison of the nursing home evacuation experience between Hurricanes Katrina (2005) and Gustav (2008). Journal of the American Medical Directors Association, 10(9), 639-643. https://doi.org/10.1016/j.jamda.2009.06.010

Bomba, P., Morrissey, M.B., \& Leven, D. (2011). Key role of social work in effective communication and conflict resolution process: Medical Orders for Life-Sustaining Treatment (MOLST) Program in New York and shared medical decision making at the end of life. Journal of Social Work in End-of-Life \& Palliative Care, 7, 56-82. https://doi.org/10.1080/15524256.2011.548047

Brown, L. M., Hyer, K., Schinka, J. A., Mando, A., Frazier, D., \& Polivka-West, L. (2010). Use of mental health services by nursing home residents after hurricanes. Psychiatric Services, 61(1), 74-77. https://doi.org/10.1176/ps.2010.61.1.74

Brown, L., Rothman, M., \& Norris, F. (2007). Issues in mental health care for older adults after disasters. Generations, 31(4), 21-26.

Castle, N. G., \& Ferguson, J. C. (2010). What is nursing home quality and how is it measured?. The Gerontologist, 50(4), 426-442. https://doi.org/10.1093/geront/gnq052

Claver, M., Dobalian, A., Fickel, J., Ricci, K.A., \& Horn Mallers, M. (2013). Comprehensive care for vulnerable elderly veterans during disasters. Archives of Gerontology \& Geriatrics, 56, 205-215. https://doi.org/10.1016/j.archger.2012.07.010

Council on Social Work Education. (2015). Educational policy and accreditation standards for baccalaureate and master's social work programs. https://cswe.org/getattachment/Accreditation/Standards-and-Policies/2015EPAS/2015EPASandGlossary.pdf.aspx 
David, P-M., Le Dévédec, N. (2019). Preparedness for the next epidemic: health and political issues of an emerging paradigm. Critical Public Health, 29(3), 363-369. https://doi.org/10.1080/09581596.2018.1447646

Donabedian, A. (1988). The quality of care: how can it be assessed?. JAMA, 260(12), 17431748. https://doi.org/10.1001/jama.1988.03410120089033

Dosa, D., Feng, Z., Hyer, K., Brown, L. M., Thomas, K., \& Mor, V. (2010). Effects of Hurricane Katrina on nursing facility resident mortality, hospitalization, and functional decline. Disaster Medicine and Public Health Preparedness, 4(0 1), S28. https://doi.org/10.1001/dmp.2010.11

Dosa, D., Hyer, K., Thomas, K., Swaminathan, S., Feng, Z., Brown, L., \& Mor, V. (2012). To evacuate or shelter in place: implications of universal hurricane evacuation policies on nursing home residents. Journal of the American Medical Directors Association, 13(2), 190-e1. https://doi.org/10.1016/j.jamda.2011.07.011

Dosa, D.M., Samsonov, M.E., \& Nace, D.A. (2003). A pilot study investigating bioterrorism preparedness in area nursing homes. JAGS, 51(S4), S117.

Dosa, D. M., Skarha, J., Peterson, L. J., Jester, D. J., Sakib, N., Ogarek, J., Thomas, K. S., Andel, R.,\& Hyer, K. (2020). Association between exposure to Hurricane IRMA and mortality and hospitalization in Florida nursing home residents. JAMA Network Open, 3(10), e2019460-e2019460. https://doi.org/10.1001/jamanetworkopen.2020.19460

Emergency Environmental Control for Nursing Homes. Fla. Stat. § 400.23 (2018). https://ahca.myflorida.com/MCHQ/Health_Facility_Regulation/Long_Term_Care/docs/N ursing_Homes/Final-Ratified_59A-4.1265.pdf 
Emergency Preparedness Requirements for Medicare and Medicaid Participating Providers and Suppliers, 81 FR 63860 (September 16, 2016). https://www.govinfo.gov/content/pkg/FR2016-09-16/pdf/2016-21404.pdf

Goldman, E. \& Galea, S. (2014). Mental health consequences of disasters. Annual Review of Public Health, 35, 169-183. https://doi.org/10.1146/annurev-publhealth-032013-182435

Hamler, T. C., English, S. J., Beltran, S. J., \& Miller, V. J. (2020). A Reflection of and Charge to Gerontological Social Work: Past Pandemics and the Current COVID-19 Crisis. Journal of Gerontological Social Work, 63(6-7), 577-579.

Holup, A. A., Hyer, K., Meng, H., \& Volicer, L. (2017). Profile of nursing home residents admitted directly from home. Journal of the American Medical Directors Association, 18(2), 131-137. https://doi.org/10.1016/j.jamda.2016.08.017

Hyer, K., Brown, L. M., Christensen, J. J., \& Thomas, K. S. (2009). Weathering the storm: challenges to nurses providing care to nursing home residents during hurricanes. Applied Nursing Research, 22(4), e9-e14. https://doi.org/10.1016/j.apnr.2008.11.001

Hyer, K., Polivka-West, L., \& Brown, L. (2007). Nursing homes and assisted living facilities: Planning and decision making for sheltering in place or evacuation. Generations, 31(4), 29-33.

Kaiser Family Foundation (2019). Average Number of Certified Nursing Facility Beds. Retrieved January 28, 2021 from https://www.kff.org/other/state-indicator/average-number-ofcertified-nursing-facilitybeds/?currentTimeframe $=0 \&$ sortModel $=\% 7 \mathrm{~B} \% 22$ colId $\% 22: \% 22$ Location $\% 22, \% 22$ sort $\%$ $22: \% 22 \operatorname{asc} \% 22 \% 7 \mathrm{D}$ 
Kusmaul, N., Bern-Klug, M. Heston-Mullins, J., Roberts, A. R., \& Galambos, C. (2020). Nursing Home Social Work During COVID-19. Journal of Gerontological Social Work, 63(6-7), 651-653. https://doi.org/10.1080/01634372.2020.1787577

Kusmaul, N., Gibson, A., \& Leedahl, S. (2018). Gerontological Social Work Roles in Disaster Preparedness and Response. Journal of Gerontological Social Work, 61(7), 692-696. https://doi.org/10.1080/01634372.2018.1510455

Ladika, S., Ladika, J., Xirasagar, S., Cornman, C., Davis, C., \& Richter, J. (2008). Providing shelter to nursing home evacuees in disasters: Lessons from Hurricane Katrina. American Journal of Public Health, 98 (7), 1288-1293. https://doi.org/10.2105/AJPH.2006.107748

Langford, T. (2011, August 5). Settlement over Hurricane Rita bus fire brings closure. Chron, https://www.chron.com/news/houston-texas/article/Settlement-over-Hurricane-Rita-busfire-brings-1736019.php

Lu, P., Kong, D., \& Shelley, M. (2020). Making the Decision to Move to a Nursing Home: Longitudinal Evidence from the Health and Retirement Study. Journal of Applied Gerontology, 1-9. https://doi.org/10.1177/0733464820949042

Medicare and Medicaid Programs; Reform of Requirements for Long-Term Care Facilities, 81 F.R. 68692 (October 4, 2016). (codified at 42 CFR $\S 405,431,447,482,483,485,488$, \& 489). https://www.federalregister.gov/documents/2016/10/04/2016-23503/medicare$\underline{\text { and-medicaid-programs-reform-of-requirements-for-long-term-care-facilities }}$

Miller, V.J., Hamler, T., Beltran, S., \& Burns, J. (2021). Nursing home social services: A systematic review of the literature from 2010 to 2020. Social Work in Health Care. [Advance Online Publication] https://doi.org/10.1080/00981389.2021.1908482 
National Association of Social Workers [NASW]. (2017). Code of ethics. https://www.socialworkers.org/About/Ethics/Code-of-Ethics/Code-of-Ethics-English National Transportation Safety Board. (2007, February 21). NTSB determines cause of bus fire in Texas that killed 23 during Hurricane Rita evacuation [Press release]. Retrieved from https://www.ntsb.gov/news/pressreleases/Pages/NTSB\%20Determines\%20Cause\%20of\%20Bus\%20Fire\%20in\%20Texas \%20that $\% 20$ Killed $\% 2023 \% 20$ during $\% 20$ Hurricane $\% 20$ Rita $\% 20$ Evacuation.aspx

Naturale, A. (2007). Secondary traumatic stress in social workers responding to disasters: Reports from the field. Clinical Social Work Journal, 35(3), 173-181. https://doi.org/10.1007/s10615-007-0089-1

Nazir, A., Unroe, K., Tegeler, M., Khan, B., Azar, J., \& Boustani, M. (2013). Systematic review of interdisciplinary interventions in nursing homes. Journal of the American Medical Directors Association, 14(7), 471-478.

Newhill, C. \& Sites, E. (2000) Identifying human remains following an air disaster. Social Work in Health Care, 31 (4), 85-105. doi: 10.1300/J010v31n04_06

Office of Inspector General (2006). Nursing home emergency preparedness and response during recent hurricanes. (OEI Publication No. 06-06-00020). U.S. Department of Health and Human Services, Office of Inspector General. https://oig.hhs.gov/oei/reports/oei-06-06-00020.pdf

Office of Inspector General (2012a). Gaps continue to exist in nursing home emergency preparedness and response during disasters: 2007-2010. (OEI Publication No. 06-0900270). U.S. Department of Health and Human Services, Office of Inspector General. https://oig.hhs.gov/oei/reports/oei-06-09-00270.asp 
Office of Inspector General (2012b). Supplemental Information Regarding the Centers for Medicare \& Medicaid Services' Emergency Preparedness Checklist for Health Care Facilities. (OEI Publication No. 06-09-00271). U.S. Department of Health and Human Services, Office of Inspector General.

Post-Katrina Emergency Management Reform Act of 2006, Pub. L. No. 109-295, 120 Stat. 1394 (2006). https://www.govinfo.gov/content/pkg/PLAW-109publ295/pdf/PLAW109pub1295.pdf

Sahlins, J. (2010). Social Work Practice in Nursing Homes: Creativity, Leadership, and Program Development. Oxford University Press.

Saliba, D., Buchanan, J., \& Kington, R.S. (2004). Function and response of nursing facilities during community disaster. American Journal of Public Health, 94(8), 1436-1441.

Schnelle, J. F., Simmons, S. F., Harrington, C., Cadogan, M., Garcia, E., \& M. Bates-Jensen, B. (2004). Relationship of nursing home staffing to quality of care. Health Services Research, 39(2), 225-250. https://doi.org/10.1111/j.1475-6773.2004.00225.x

Scoville, M. C. (1942). Wartime tasks of psychiatric social workers in Great Britain. American Journal of Psychiatry, 99(3), 358-363.

Shippee, T., Hong, H., Henning-Smith, C., \& Kane, R. (2015). Longitudinal changes in nursing home resident-reported quality of life: The role of facility characteristics. Research on Aging, 37(6), 555-580. https://doi.org/10.1177/0164027514545975

Simons, K.V. (2006). Organizational characteristics influencing nursing home social service directors' qualifications: A national study. Health and Social Work 31(4), 266-74. 
Table 1:

Chi Square Test of Individual Predictors and Social Service Involvement in Disaster Preparedness and Response

\begin{tabular}{lcccc}
\hline & $X^{2}$ & $d f$ & p-value & $N$ \\
\cline { 2 - 5 } Gender & 2.36 & 2 & .31 & 908 \\
Race & 2.48 & 2 & .29 & 917 \\
Education & 5.48 & 4 & .242 & 906 \\
Experience & 4.30 & 4 & .37 & 915 \\
Social Work License & 1.30 & 2 & .52 & 901 \\
\hline
\end{tabular}


Table 2

Logistic Regression Model of Social Service Involvement in Disaster Preparedness and Response

\begin{tabular}{|c|c|c|c|c|}
\hline \multirow[b]{3}{*}{ Gender (Male) } & \multicolumn{2}{|c|}{ Step One } & \multicolumn{2}{|c|}{ Step 2} \\
\hline & OR & $95 \% \mathrm{CI}$ & OR & $95 \% \mathrm{CI}$ \\
\hline & .84 & {$[.50,1.39]$} & .84 & {$[.50,1.41]$} \\
\hline \multicolumn{5}{|l|}{ Age } \\
\hline $18-34$ & $.46^{* * *}$ & {$[.29, .71]$} & $.45 * * *$ & {$[.29, .70]$} \\
\hline $35-54$ & $.51 * * *$ & {$[.36, .73]$} & $.50 * * *$ & {$[.35, .73]$} \\
\hline Race (White) & 1.01 & {$[.66,1.55]$} & 1.06 & {$[.68,1.66]$} \\
\hline \multicolumn{5}{|l|}{ Education Level } \\
\hline$<4$ Year Degree & 1.18 & {$[.73,1.90]$} & 1.31 & {$[.79,2.20]$} \\
\hline Bachelor Degree & .95 & {$[.69,1.31]$} & .99 & {$[.71,1.38]$} \\
\hline \multicolumn{5}{|l|}{ Experience } \\
\hline 0-3 Years & .93 & {$[.64,1.37]$} & .93 & {$[.62,1.40]$} \\
\hline 4-9 Years & .81 & {$[.56,1.16]$} & .81 & {$[.56,1.17]$} \\
\hline No Social Work License & .82 & {$[.60,1.12]$} & .81 & {$[.59,1.11]$} \\
\hline Bed Size & $\cdots$ & --- & & \\
\hline$<60$ Beds & - & --- & 1.29 & {$[.78,2.15]$} \\
\hline $60-120$ Beds & & & .95 & {$[.67,1.34]$} \\
\hline Ownership & --- & - & 1.11 & {$[.82,1.51]$} \\
\hline Rural/Urban & --- & -- & 1.34 & {$[.97,1.88]$} \\
\hline Staffing Ratio & --- & -- & .99 & {$[.84,1.17]$} \\
\hline Region & --- & --- & & \\
\hline Northeast Coastal & --- & --- & 1.15 & {$[.72,1.86]$} \\
\hline South Coastal & --- & --- & 1.10 & {$[.76,1.87]$} \\
\hline Pacific Coastal & --- & --- & .92 & {$[.52,1.65]$} \\
\hline Wildfire States $†$ & --- & --- & .73 & {$[.43,1.23]$} \\
\hline
\end{tabular}

Note: UOR = Unadjusted Odds Ratio; AOR = Adjusted Odds Ratio; CI = Confidence Interval. Reference Groups: Gender- Female; Age- 55+; Race- Other; Education Level- Master's Degree; Experience- more than 10 years; Bed Size- more than 120, Ownership- For profit, Rural/UrbanUrban, Staffing ration- continuous variable, Region- non-coastal; and Wildfire states- noncoastal.

$\dagger$ Census Regions were recoded into wildfire areas and included in a separate regression model in place of Coastal region. $*_{p}<.05, * *_{p}<.01, * * * p<.001$ 